\title{
APLICATION OF OBJECT-BASED ACCURACY ASSESSMENT FOR LAND COVER CLASSIFICATION USING RAPIDEYE IMAGES IN SOUTHEASTERN BRAZIL
}

\author{
D. F. C. Prado ${ }^{\text {a }}$, L. M. T. Carvalho ${ }^{\text {a } *}$ \\ ${ }^{\text {a }}$ Federal University of Lavras - UFLA, Lavras, Brazil-danfernando010@gmail.com, passarinho@dcf.ufla.br.
}

KEY WORDS : Validation, Sampling, Thematic accuracy, Object geometry, Similarity measurements

\begin{abstract}
:
Maps of land cover generated by Geographic Object-Based Image Analysis (GEOBIA) approach provide several advantages in relation to the pixel-based methodology, thus leading to significant gains for the accuracy of the final map. The accuracy indices that frequently express such gains are obtained from the traditional pixel-based validation. Then, given the absence of a validation representing the geographical object, new object-based methodologies to assess the accuracy have been developed with the similarity matrix STEP (Shape, Thematic, Edge and Position). In this sense, from the STEP methodology, this study aims to evaluate the thematic and geometric accuracy of land cover mapping generated by GEOBIA, as well as identify and analyse the main sources of errors. The study area is located in the municipalities of São José do Barreiro (São Paulo state) and Resende (Rio de Janeiro state), Southeastern Brazil. The map of land cover was generated from RapidEye Images acquired in year of 2011, with $5 \mathrm{~m}$ of spatial resolution. The global accuracy of the classification in relation to the traditional matrix was of $92 \%$. The methodology integrates four similarity measurements (Shape, Thematic, Edge and Position), each one generating two error matrices (individual and aggregate thematic class). A global thematic accuracy of $76.6 \%$ was obtained, and for the measurements position (81.8\%), edge (99.1\%) and shape $(93.3 \%)$. The methodology may be considered applicable and effective to validate thematic maps generated by GEOBIA. However, there are some limitations to be considered in relation to the size and extent of the objects.
\end{abstract}

\section{INTRODUCTION}

Remote sensing consists in a wide and attractive source for making maps, which enable the description of information on land cover through representations of the land surface (Foody, 2002). Furthermore, remote sensing has been showed to be useful in agriculture ( $\mathrm{Li}$ et al, 2016), urban analy sis (Zang \& Du, 2016), in change detections ( $\mathrm{Yu}$ et $\mathrm{al}, 2016$ ) and in the monitoring the vegetation at local, regional (Kempneers et al, 2013) and global scales (Homer et al, 2007, Xian et al, 2011)

Such information may be used for several purposes, like supporting public policies, decision making and scientific researches. In this sense, the accuracy of this information is determinant when using these products, what requires the measurement of the accuracy level, thus establishing a reliability parameter of the product.

Problems related to the inaccuracy of thematic maps may be influenced by several factors from the moment of data acquisition to the processing and generation of the final product. Characteristics like heterogeneity, shape and extension of targets or lack of experience of the interpreter may cause errors during the image analysis, thus decreasing its accuracy level.
Some constraints regarding the accuracy of cartographic products are also related to the source data, it means, the images. The design of targets and their allocation may be influenced by distortions caused during their acquisition. Nowadays it is possible to work with high-resolution and highly geometrically accurate images in function of advances on orbital remote sensors and pre-processing of images, for example the launch of a constellation with five RapidEye satellites in 2008 (BLACKBRIDGE, 2013). High-quality data provide more detailed information without distortions.

Additionally, new methodologies have been developed to improve techniques of aut omated classification. The Geographic Object-Based Image Analysis (GEOBIA) is a recent approach used to classify images supported by the object-based paradigm, which includes the location and spatial context as keycomponents of the analy sis (Hay and Castilla, 2008).

GEOBIA is a useful approach for mapping the land cover, since it allows a more significant classification of the landscape when compared to traditional pixel-based methods of image processing, especially using high-resolution spatial data (BLASCHKE and STROBL, 2001; ZHOU and TROY, 2008).

* Corresponding author 
In this sense, high-resolution data allied to new methodologies of analysis, such as those based in objects, have an enormous potential for generating information. On the other hand, there is a great challenge to evaluate such information, since the traditional pixel-based assessment is still used for this type of product. The assessment of thematic and geometric accuracy is one of the main challenges when using the object-based approach, but some methodologies have been developed in order to substitute the traditional ones (PERSELLO and BRUZONE, 2010; HERNANDO et al, 2012; MÖLLER et al, 2013, MÖLLER, BIRGER, GLÄSSER, 2014; LIZARAZO, 2014).

Identifying the source of errors of data classification is fundamental to measure the reliability of thematic maps. In this sense the present work aimed to assess the thematic and geometric accuracy of land cover mapping generated from RapidEye images, as well as identify and analyzed the main sources of errors in the generated product.

\section{STUDY AREA}

The study area is situated in Southeastern Brazil in the frontier between the municipalities of São José do Barreiro and Resende, São Paulo and Rio de Janeiro states, respectively. The land cover is compounded by fragments of Atlantic Forest, pasture, urban areas, small eucalypt crops and water bodies, with a total area of 2991.47 hectares, according to Figure 1.

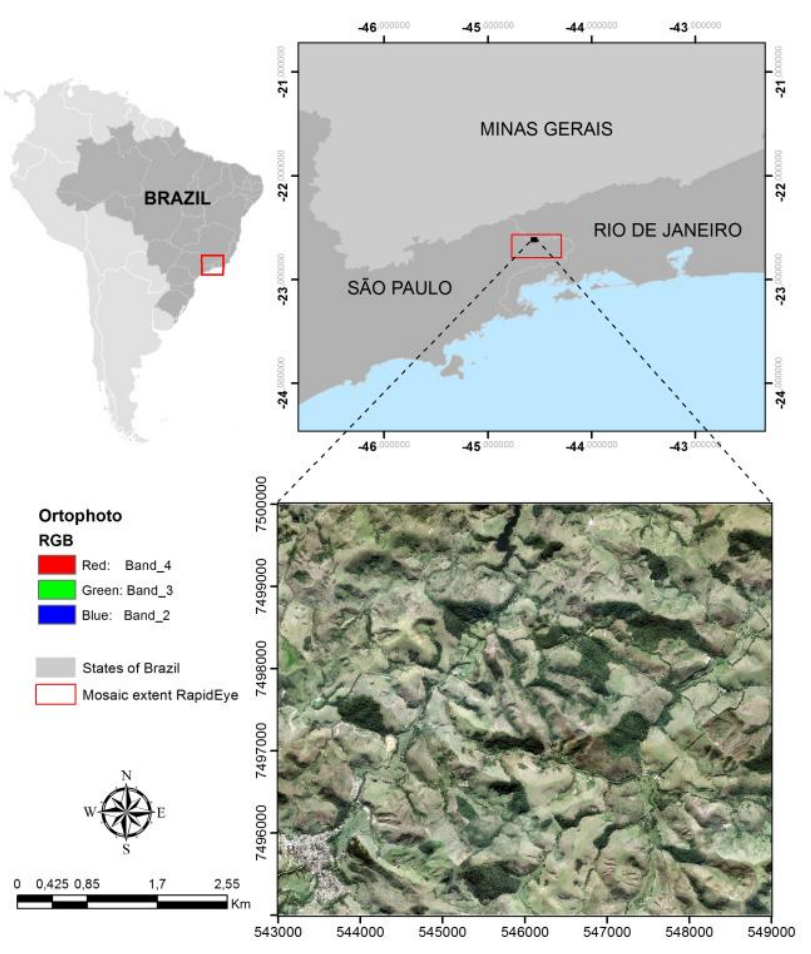

Figure 1. Localization of the study area.

\section{MATERIAL AND METHODS}

\subsection{Satellite images}

RapidEye images corresponding to the tiles 2328617 and 2328616 with acquisition dates in 09/27/2011 and 08/16/2011, respectively, were used to classify the land cover in the study area. The images have spatial resolution of $5 \mathrm{~m}$ and 5 spectral bands: Blue (B), Green (G), Red (R), Red-Edge(R-edge) and Infra-red (IR). The images were provided by Ministério do Meio Ambiente (MMA) and were mosaicked, since the study area is situated in the frontier between images. An ortophoto from 2012 with $0.4 \mathrm{~m}$ of spatial resolution and 4 spectral bands (B, G, R, NIR) was used for the collection of reference samples.

\subsection{Image classification}

The thematic classification of RapidEye images was made through GEOBIA. The included classes were vegetation (fragments of forests and areas of natural vegetation), anthropic area (pasture, crops, exposed soil and areas of human intervention), urban area (conurbations, cities and districts) and water bodies. The class anthropic area represented $81.39 \%$ of all the studied area, followed by the classes vegetation (17.36\%), urban area $(1.14 \%)$ and water bodies $(0.11 \%)$. The area of analysis is limited to the ortophoto extension, what led to the reduction of thematic classification for comparisons among objects. Overall the classification resulted in 184 classified objects that comprised 152 objects of vegetation, 22 of anthropic area, 9 objects of water bodies and 3 of urban area. The thematic classification attained a global accuracy of $92 \%$ and 0.74 for the Kappa coefficient.

\subsection{Reference data}

In order to obtain the global accuracy based on the traditional error matrix (Congalton and Green, 1999), 200 random sampling points were distributed proportionally to the area of each class. For each point one thematic class corresponding to the ground truth was attributed. The targets were manually vectorized from the sampling points to represent the reference objects based on the ortophoto. Overall, 13 reference objects were digitized, which comprised 10 objects of vegetation and one for each of the other classes. The class anthropic area presented the largest area and more sampling points. However, since this class comprises almost all the extension of the area continuously, it resulted in only one reference object.

\subsection{Accuracy analysis}

The method proposed by Lizarazo (2014) makes a thematic and geometric validation for classification data generated by GEOBIA. The analysis consists on comparing corresponding classified objects and reference objects, it means, those with intersection. The reference object is the analysis parameter, in 
which all corresponding objects are analyzed. Based on the correspondence, the indexes of thematic and geometric similarity among objects are calculated: Shape, Theme, Edge and Position. Each index is calculated individually for each object, the value for each cell results in an interval ranging from 0 to 1 in which 0 corresponds to any similarity and 1 to total similarity.

The index of shape similarity (S) is calculated in relation to the normalized perimeter index (NPI) of each object (classified and reference) (Angel, Parent and Civco, 2010). The index is the results of the ratio between the circular perimeter with equal area $\left(P_{e a c}\right)$ and the perimeter of the analyzed object $\left(P_{o b j}\right)$ according to Equation 1. The ratio among NPIs of objects expresses the shape similarity, in which the $k$ value is 1 when the ratio $\mathrm{r}_{n p i}$ is equal to or lower than 1.0, otherwise the $k$ value is -1 according to Equation 2.

$$
\mathrm{NPI}=P_{e a c} / P_{o b j} \quad \text { (1) } \quad S=\mathrm{r}_{n p i}{ }^{k}
$$

The index of theme similarity $(\mathrm{T})$ is calculated by the percentage of intersection area between the reference object and classified object divided by the area of the reference object $\left(A_{\text {ref }}\right)$ according to Equation 3.

$$
T=A_{\text {int }} / A_{\text {ref }}
$$

The index of edge similarity (E) is calculated through the percentage of the edge length coincident between the classified object and the reference object $\left(l_{\text {int }}\right)$ in relation to the total edge length of the reference object $\left(p_{r e f}\right)$. The index of edge similarity is expressed by Equation 4. The $k$ value is attributed to 1 when $l_{\text {int }}$ is lower than or equal to $p_{\text {ref }}$, otherwise $k$ is equal to -1 .

$$
E=\left(l_{i n t} / p_{r e f}\right)^{\mathrm{k}}
$$

A "width" is considered in relation to the edge of reference data, namely the Epsilon Band, which is defined as a zone of uncertainty around an encoded line within which there is a certain probability of observing the 'actual' line (Lizarazo, 2014). This distance is based in the spatial accuracy of reference data that in this case was $1.25 \mathrm{~m}$ with $95 \%$ of confidence level.

Finally, the index of position similarity is calculated based on the position of the objects centroid. The index consists on dividing the Euclidian distance between corresponding centroids $\left(d_{\text {cent }}\right)$ by the diameter of the combined circular area of the reference object and the classified object $\left(d_{\text {cac }}\right)$ according to Equation 5. $d_{\text {cac }}$ corresponds to the diameter of the circle with area equal to the sum of the corresponding objects.

$$
P=1-d_{\text {cent }} / d_{\text {cac }}
$$

The results expressed by the indexes of similarity are presented in a matrix in which rows correspond to the reference objects and columns to the classified objects. The values contained in each cell consist in the similarity values of the corresponding objects. Objects without correspondence are expressed with value 0.00 in the matrix.
Resultant values of the individual similarity matrix are summarized in a similarity matrix aggregated by thematic classes. The matrix is constructed by aggregating lines and columns of the individual matrix in which the resultant number of rows and columns correspond to the number of thematic classes. The aggregation of line and columns is conducted separately. The aggregation of columns is made in relation to the reference objects according to Equation 6. For the aggregation of theme index, $\mathrm{T}_{j}$ is the aggregated value of the theme index $(\mathrm{T})$ of the reference object $j, \mathrm{a}_{\mathrm{i}}$ is the percentage of the reference area occupied by the object $i$ and $\mathrm{T}_{i}$ is the theme value of object $i$.

$$
T_{j}=\sum_{i=1}^{n}\left(a_{i} T_{i}\right)
$$

The aggregation of lines is made according to the weight of each reference object. The weight (Equation 7) is calculated from the probability of one reference object be selected within its thematic category (Equation 8). The aggregation of lines is conducted according to Equation 9, in which $\mathrm{T}_{a g}$ is the aggregated value of the theme index for each thematic category; $\mathrm{w}_{\mathrm{j}}$ is the weight given to the reference object $j$, and $\mathrm{T}_{j}$ is the resultant value of the theme index for the object $j$.

$$
w_{j}=\frac{1}{p_{j}} \quad \text { (7) } \quad P_{j}=\frac{a_{j}}{A_{c}} \quad \text { (8) } \quad T_{a g}=\frac{\sum_{j=1}^{n}\left(w_{j} T_{j}\right)}{\sum_{j=1}^{n}\left(w_{j}\right)}
$$

Furthermore, in order to compensate the differences of areas sampled by thematic category, the method still proposes an analy sis of aggregated matrix by thematic class weighted by area, in which values of area superimposed on the reference object of each cell of the aggregated matrix is weighted according to the normalized weight for its thematic category.

The normalized weight is obtained from the ratio between the simple weight of one category and the sum of weights of all categories. The simple weight of each class $\left(\mathrm{W}_{\mathrm{x}}\right)$ is calculated by the Equation 10 as the ratio between the total sampled area $\left(A_{t}\right)$ and the sampled area of each category $\left(a_{x}\right)$.

$$
\mathrm{W}_{\mathrm{x}}=\mathrm{A}_{\mathrm{t}} / \mathrm{a}_{\mathrm{x}}
$$

From the weighted matrix the producer, user and global accuracy corresponding to each index (Shape, Theme, Edge and Position) was calculated.

\section{RESULTS AND DISCUSSION}

Similarity matrices for each index (Shape, Theme, Edge and Position) were constructed from the comparison of individual objects. Only similarity matrices aggregated by thematic classes and matrices weighted by area were used for a general analysis of classes. Table 1 presents the results of similarity matrices aggregated by thematic class. In the aggregated similarity matrix of theme the class anthropic area presented the better results, with 0.96 , followed by urban area with 0.91 . The classes 
vegetation and water bodies presented the lowest values, 0.79 and 0.75 , respectively.

\begin{tabular}{|c|c|c|c|c|}
\hline & Theme & & & \\
\hline True / Class & Anthropic & Vegetation & Water & Urban \\
\hline Antropic & 0.96 & 0.04 & 0.00 & 0.00 \\
\hline \begin{tabular}{|l|} 
Vegetation \\
\end{tabular} & 0.21 & 0.79 & 0.00 & 0.00 \\
\hline \begin{tabular}{|l|} 
Water \\
\end{tabular} & 0.02 & 0.22 & 0.75 & 0.00 \\
\hline \multirow[t]{2}{*}{\begin{tabular}{|l|} 
Urban \\
\end{tabular}} & 0.08 & 0.01 & 0.00 & 0.91 \\
\hline & Edge & & & \\
\hline True / Class & Anthropic & Vegetation & Water & Urban \\
\hline Antropic & 0.55 & 0.00 & 0.00 & 0.00 \\
\hline \begin{tabular}{|l|} 
Vegetation \\
\end{tabular} & 0.12 & 0.64 & 0.00 & 0.00 \\
\hline \begin{tabular}{|l|} 
Water \\
\end{tabular} & 0.02 & 0.21 & 0.69 & 0.00 \\
\hline \multirow[t]{2}{*}{\begin{tabular}{|l} 
Urban \\
\end{tabular}} & 0.03 & 0.00 & 0.00 & 0.70 \\
\hline & Shape & & & \\
\hline True / Class & Anthropic & Vegetation & Water & Urban \\
\hline Antropic & 0.87 & 0.01 & 0.00 & 0.00 \\
\hline \begin{tabular}{|l|} 
Vegetation \\
\end{tabular} & 0.05 & 0.69 & 0.00 & 0.00 \\
\hline \begin{tabular}{|l|} 
Water \\
\end{tabular} & 0.02 & 0.04 & 0.60 & 0.00 \\
\hline \multirow[t]{2}{*}{\begin{tabular}{|l|} 
Urban \\
\end{tabular}} & 0.04 & 0.01 & 0.00 & 0.83 \\
\hline & Position & & & \\
\hline True / Class & Anthropic & Vegetation & Water & Urban \\
\hline \begin{tabular}{|l} 
Antropic \\
\end{tabular} & 0.95 & 0.03 & 0.00 & 0.00 \\
\hline \begin{tabular}{|l|} 
Vegetation \\
\end{tabular} & 0.00 & 0.68 & 0.00 & 0.00 \\
\hline \begin{tabular}{|l|} 
Water \\
\end{tabular} & 0.00 & 0.00 & 0.73 & 0.00 \\
\hline \begin{tabular}{|l} 
Urban \\
\end{tabular} & 0.01 & 0.00 & 0.00 & 0.89 \\
\hline
\end{tabular}

Table 1. Matrix aggregated by thematic class of Theme, Shape, Edge and Position similarities.

The vegetation of the studied area consists in forest fragments, most of them linked by corridors. Differences between canopy size, textural variations in the image or shaded areas were also common in the area, which also have a more rugged relief. Such factors may cause errors of classification in function of the design of vegetation objects.

The class vegetation presented the lowest value in the aggregated matrix of position in relation to the other classes (0.68). According to Figure 2-A, errors in classification like disjoint classified objects, cause great difference between the position of objects centroids. In this case, both the number of centroids analyzed and the distance among them increases, what decreases the level of positional accuracy.

During the construction of the individual similarity matrix of position, negative values were observed in some cells, which correspond to the intersection between objects of different classes. Negative values occur when the distance of centroid $\left(d_{\text {cent }}\right)$ among objects is greater than the value of circular diameter with the same area $\left(d_{c e a}\right)$ (equation 5). In this case, the analysis of several different classes of objects presented a large distance between the centroids (Figure 3), thus generating negative values. These negative values were assigned to objects without any positional correspondence and were considered the value 0.00 in the individual similarity matrix.
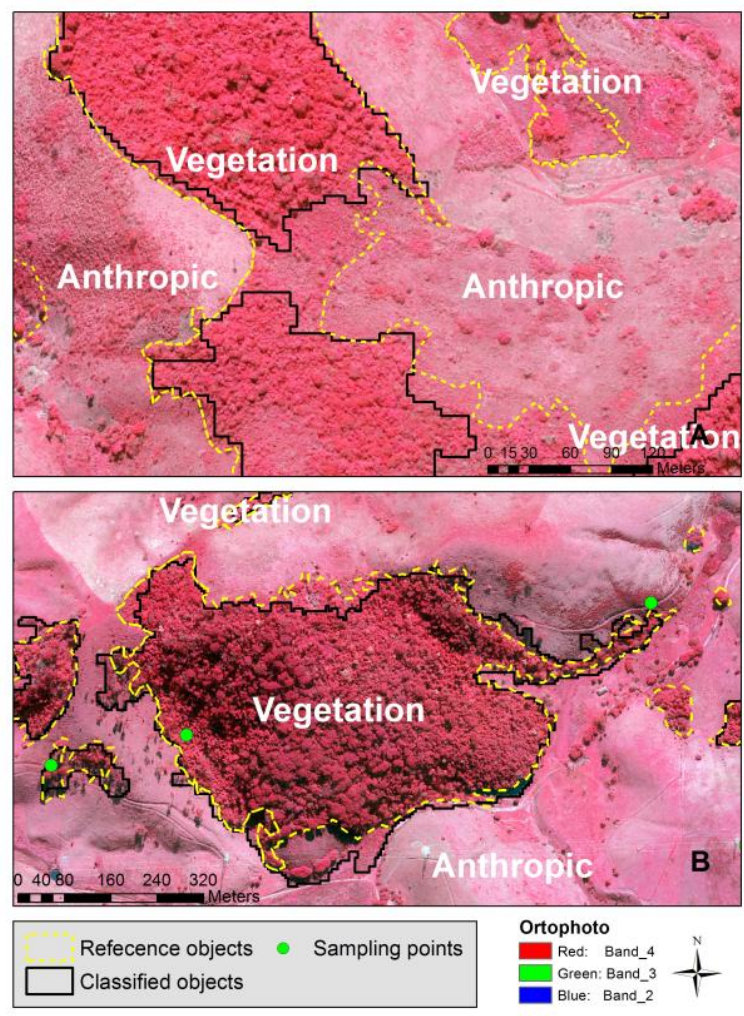

Figure 2A - Error in the discontinuity of the classified object. B - Differences between the edge of objects.

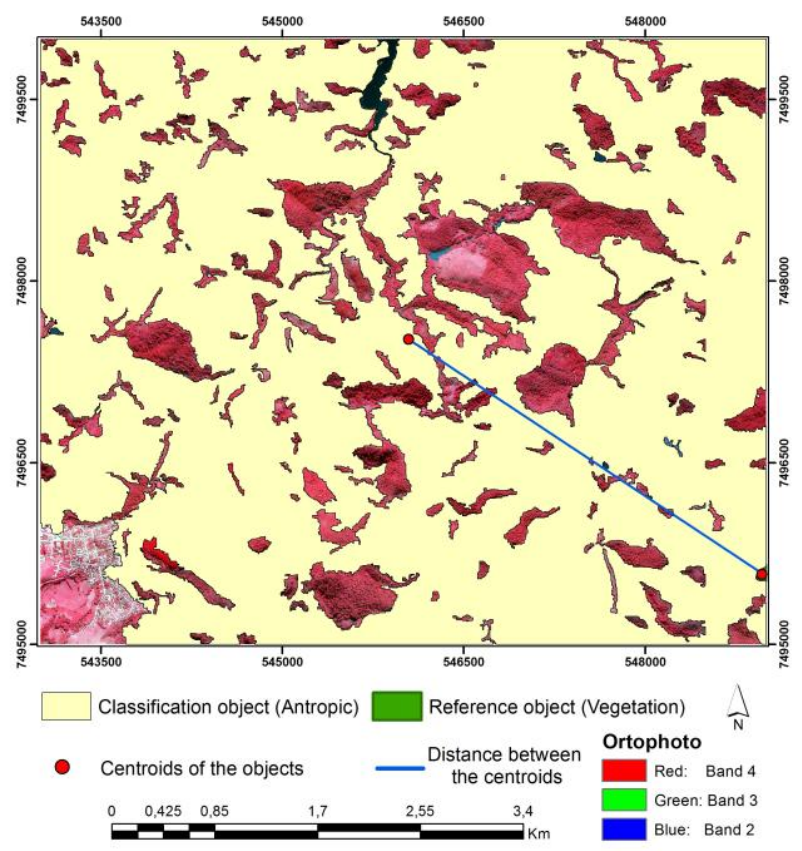

Figure 3. An example of the distance between objects with low correlation and different classes.

The similarity matrix of edge presented the lowest results in all the classes. In this matrix the anthropic area presented the lowest accuracy level (0.55). Problems related to the non- 
correspondence of edge often occur as in Figure 2B, for example, which are caused by classification errors and differences between the design of objects.

The weighted error matrix aims to compensate the differences of area in relation to the size of reference objects. Thus, classes with large areas receive low weight, while classes with small areas receive higher weights (Table 2).

\begin{tabular}{l|r|l|c} 
Class & $\begin{array}{c}\text { Reference object } \\
\text { area }\end{array}$ & $\begin{array}{l}\text { Simple } \\
\text { weigth }\end{array}$ & $\begin{array}{c}\text { Normalized } \\
\text { weigth }\end{array}$ \\
\hline Anthropic & 23438514 & 1.113327 & 0.000413 \\
\hline Vegetation & 2298875 & 11.35109 & 0.004209 \\
\hline Water & 10000.32 & 2609.391 & 0.967523 \\
\hline Urban & 347348.8 & 75.12547 & 0.027855
\end{tabular}

Table 2. Weight values for each thematic class

It is possible to observe in the weighted error matrix of theme (Table 3) that the class anthropic area presented the lowest producer accuracy $(50.33 \%)$. On the other hand, the class urban area obtained the highest producer $(99.77 \%)$ and user accuracy $(99.68 \%)$. The lowest values of user accuracy were obtained by the classes vegetation and water bodies, with $65.9 \%$ and $56.58 \%$, respectively. The global accuracy of the thematic similarity index was $76.67 \%$.

The highest percentage of error was observed for the classes vegetation and water bodies, which have the highest percentage of area within other reference object, therefore it is the anthropic class that receives the greater amount of area. This also reflects in a high omission error for the class anthropic area.

The weighted matrix of edge presented the highest results, with global accuracy of $98.73 \%$ and producer and user accuracy between $96.11 \%$ and $100 \%$. The values presented in the weighted error matrix for this index were more satisfactory than those presented by the aggregated matrix, what occurs because the area of edge overlap of different classes is smaller when compared to the correspondence area of objects. Thus, the omission and commission errors are low in relation to the weighted area of objects.

Results of shape and position weighted matrices presented global accuracy of $92.21 \%$ and $82.10 \%$, respectively. The classes vegetation and water bodies also presented the lowest values of user accuracy $(79.55 \%$ and $85.88 \%$ for shape and $62.68 \%$ and $66.08 \%$ for position, respectively), while the class anthropic area presented the lowest values of producer accuracy ( $81.04 \%$ for shape and $61.07 \%$ for position).

In relation to results by thematic class, it is possible to observe that the higher omission and commission errors repeated among the classes anthropic area, vegetation and water bodies. Therefore, there is an evident direct relationship between the errors of thematic classification and errors regarding the geometry of objects (shape, edge and position). In this study, only the edge similarity did not present the same cases of error in relation to the weighted area.

\begin{tabular}{|c|c|c|c|c|c|c|}
\hline & & Theme & & & & \\
\hline True / Class & Anthropic & Vegetation & Water & Urban & Total & Prod. Acc \\
\hline Antropic & 9247.22 & 4335.39 & 4763.48 & 26.37 & 18372.5 & $50.33 \%$ \\
\hline \begin{tabular}{|l} 
Vegetation \\
\end{tabular} & 123.34 & 8414.37 & 829.14 & 0.00 & 9366.85 & $89.83 \%$ \\
\hline Water & 0.10 & 9.35 & 7288.71 & 0.00 & 7298.17 & $99.87 \%$ \\
\hline Urban & 11.67 & 9.10 & 0.00 & 8827.82 & 8848.59 & $99.77 \%$ \\
\hline Total & 9382.33 & 12768.22 & 12881.33 & 8854.19 & 43886.1 & \\
\hline \multirow[t]{2}{*}{ User Acc. } & $98.56 \%$ & $65.90 \%$ & $56.58 \%$ & $99.70 \%$ & & $76.97 \%$ \\
\hline & & Edge & & & & \\
\hline True / Class & Anthropic & Vegetation & Water & Urban & Total & Prod. Acc \\
\hline Antropic & 5337.66 & 208.14 & 7.75 & 0.06 & 5553.61 & $96.11 \%$ \\
\hline \begin{tabular}{|l|} 
Vegetation \\
\end{tabular} & 75.38 & 5809.07 & 10.93 & 0.00 & 5895.38 & $98.54 \%$ \\
\hline Water & 0.07 & 8.70 & 6632.73 & 0.00 & 6641.5 & $99.87 \%$ \\
\hline \begin{tabular}{|l} 
Urban \\
\end{tabular} & 3.94 & 0.71 & 0.00 & 6709.14 & 6713.79 & $99.93 \%$ \\
\hline Total & 5417.04 & 6026.62 & 6651.41 & 6709.20 & 24804.3 & \\
\hline \multirow[t]{2}{*}{ User Acc. } & $98.53 \%$ & $96.39 \%$ & $99.72 \%$ & \begin{tabular}{|l|}
$100.00 \%$ \\
\end{tabular} & & $98.73 \%$ \\
\hline & & Shape & & & & \\
\hline True / Class & Anthropic & Vegetation & Water & Urban & Total & Prod. Acc \\
\hline \begin{tabular}{|l|} 
Antropic \\
\end{tabular} & 8472.09 & 1289.57 & 685.49 & 6.59 & 10453.7 & $81.04 \%$ \\
\hline \begin{tabular}{|l} 
Vegetation \\
\end{tabular} & 43.37 & 5053.39 & 273.42 & 0.00 & 5370.18 & $94.10 \%$ \\
\hline \begin{tabular}{|l} 
Water \\
\end{tabular} & 0.08 & 1.50 & 5830.97 & 0.00 & 5832.54 & $99.97 \%$ \\
\hline $\begin{array}{l}\text { Urban } \\
\end{array}$ & 5.32 & 7.65 & 0.00 & 8033.31 & 8046.29 & $99.84 \%$ \\
\hline Total & 8520.87 & 6352.12 & 6789.87 & 8039.91 & 29702.8 & \\
\hline \multirow[t]{2}{*}{ User Acc. } & $99.43 \%$ & $79.55 \%$ & $85.88 \%$ & $99.92 \%$ & & $92.21 \%$ \\
\hline & & Position & & & & \\
\hline True / Class & Anthropic & Vegetation & Water & Urban & Total & Prod. Acc \\
\hline Antropic & 9240.78 & 2866.92 & 3013.30 & 10.81 & 15131.8 & $61.07 \%$ \\
\hline \begin{tabular}{|l|} 
Vegetation \\
\end{tabular} & 2.48 & 4819.91 & 578.22 & 0.00 & 5400.6 & $89.25 \%$ \\
\hline \begin{tabular}{|l} 
Water \\
\end{tabular} & 0.00 & 0.00 & 6997.17 & 0.00 & 6997.17 & $100.00 \%$ \\
\hline \begin{tabular}{|l} 
Urban \\
\end{tabular} & 1.92 & 2.28 & 0.00 & 8651.26 & 8655.47 & $99.95 \%$ \\
\hline Total & 9245.18 & 7689.11 & 10588.68 & 8662.07 & 36185.1 & \\
\hline User Acc. & 99.95\% & $62.68 \%$ & $66.08 \%$ & $99.88 \%$ & & $82.10 \%$ \\
\hline
\end{tabular}

Table 3. Weighted error matrix of theme, edge, shape and position.

Regarding global results, it is possible to observe that similarities of shape and edge obtained the highest success (more than 90\%). On the other hand, the similarity of position obtained a global accuracy of $82.1 \%$ and theme similarity of $76.97 \%$.

In an object-based accuracy analysis we may consider that geometric and thematic characteristics affect directly results of both of them. However, in general the theme and position similarities are the responsible by classification errors detected in the thematic map.

\section{CONCLUSION}

The method is able to assess jointly the thematic and positional accuracy of a thematic map with efficiency. The object-based assessment provided a more detailed analysis of the thematic product, thus allowing to observe how the inconsistencies between objects may reflect misclassification. Classification errors were well identified and measured by the method both in relation to the thematic and geometric information, what represents a great advantage in relation to traditional pixel-based analy ses. 


\section{ACKNOWLEDGMENTS}

I thank Fundação de Amparo à Pesquisa de Minas Gerais FAPEMIG for financial support and Coordenação de Aperfeiçoamento de Pessoal de Nível Superior - CAPES - for the scholarship provided.

\section{REFERENCES}

Angel, S., Parent, J., Civco, D. L., 2010. Ten compactness properties of circles: measuring shape in geography. The Canadian Geographer, 4 (54).

Blackbridge. Satellite Imagery Product Specifications. 2015.

Blaschke, T., Strobl, J., 2001. What's wrong with pixels? Some recent developments interfacing remote sensing and GIS. GISZeitschrift für Geoinformationssy steme 14 (6), 12-17.

Congalton, R. G., \& Green, K. ,1999. Assessing the accuracy of remotely sensed data: principles and practices. Boca Raton, FL: Lewis Publishers, pp.137.

Foody, G. M., 2002.Status of land cover classification accuracy assessment. Remote Sensing of Environment 80, pp. 185-201.

Hay, G.J., Castilla, G., 2008. Geographic object based image analysis: a new name for a new discipline.In: T. Blaschke, S. Lang, and G. Hay, (eds.), Object-based image analysis. Berlin:Springer, pp.91-111.

Hernando, G. M., D. Tiede, F. Albrecht, and S. Lang, 2012. Spatial and Thematic Assessment of Object-based Forest Stand Delineation Using an OFA-matrix. International Journal of Applied Earth Observation and Geoinformation 19, pp. 214225.

Homer, C. G., Dewitz, J., Coan, M., Hossain, N., Larson, C., Herold, N., et al., 2007. Completion of the 2001 National Land Cover Database for the conterminous United States. Photogrammetric Engineering and Remote Sensing, 73, pp. 337 341 .

Kempeneers, P., McInerney, D., Sedano, F., Gallego, J., Strobl, P, Kay, S., Korhonen, K. T., San-Miguel-Ayanz, J., 2013. Accuracy Assessment of a Remote Sensing-Based, PanEuropean Forest Cover Map Using Multi-Country National Forest Inventory Data. IEEE Journal of selected topics in applied earth observations and remote sensing, 6 (1).

Li, M., Ma, L., Blaschke, T., Chenga, L., Tiede, D., 2016. A systematic comparision of different object-based classification techniques using high spatial resolution imagery in agriculture enviroments. International journal of applied earth observation and geoinformation, 49, pp. 87-98.
Lizarazo, I., 2014. Accuracy assessment of object-based image classification: another STEP. International journal of remote sensing., 16 (35), pp. 6135-6156.

Möller, M., Birger, J., Gidudu, A., Glässer, C., 2013. A Framework for the Geometric Accuracy Assessment of Classified Objects." International Journal of Remote Sensing 34 , pp. 8685-8698.

Möller, M., Birger, J., Glässer, C., 2014. Geometric Accuracy Assessment of Classified Land Use/Land Cover Changes. Photogrammetrie - Fernerkundung - Geoinformation, 2, pp. 91100.

Persello, C., Bruzzone, L., 2010. A Novel Protocol for Accuracy Assessment in Classification of Very High Resolution Images. IEEE Transactions on geoscience and remote sensing, 48 (3), pp. 1232-1244.

Xian, G., Homer, C., Dewitz, J., Fry, J., Hossain, N., \&Wickham, J. (2011). Change of impervious urface area between 2001 and 2006 in the conterminous United States. Photogrammetric Engineering and Remote Sensing, 77,758-762.

Yu, W., Zhou, W., Qian, Y., Yan, J., 2016. A new approach for land cover classification and change analysis: Integrating backdating and an object-based method. Remote Sensing of Environment, 177, pp. 37-47.

Zhang, X., Du, S., 2016. Learning selfhood scales for urban land cover mapping with very-high-resolution satellite images. Remote Sensing of Environment 178, pp. 172-190.

Zhou,W. Q., \& Troy, A. (2008). An object-oriented approach for analysing and character- izing urban landscape at the parcel level. International Journal of Remote Sensing, 29, 3119-3135. 